Original Article

\title{
Management of early years of simple and mucopurulent chronic bronchitis with pre-defined homeopathic medicines - a Prospective Observational Study with 2-Years Follow-Up
}

\author{
Jaya Gupta 1; M. Prakash Rao 2; Kolli Raju 3; RVR. Prasad 4; JS Arya 5; BK Mondal 6;
} Gopinadhan Sadanandan 7; Mohan Singh 8; Vikram Singh 9; Chaturbhuja Nayak 10; Abhishek Pramanik 11; Sh. Arvind Kumar ${ }^{12}$; Varanasi Roja* 13

1 - Central Council for Research in Homoeopathy, Hqrs, New Delhi; igupta21@gmail.com

2 - Clinical Research Unit (H), Puducherry; drmprakashrao@gmail.com

3 - Homoeopathic Research Institute of Disabilities, Chennai, Tamil Nadu; bhogirajukolli62@gmail.com

4 - Clinical Research Unit (H), Tirupati, Andhra Pradesh; rvrprasad60@yahoo.com

5 - Clinical Research Unit (H), Siliguri, West Bengal; cruslg@gmail.com

6 - Regional Research Institute (H), Puri, Odisha; rri puri@yahoo.co.in

7 - National Homoeopathic Research Institute for Mental Health, Kottayam, Kerala; dr.sgopinadhan@gmail.com

8 - Dr. DP Rastogi Central Research Institute (H), Noida; crihnoida@gmail.com

9 - Central Council for Research in Homoeopathy, Hqrs, New Delhi; vsinghdr@yahoo.co.in

10 - Former Director General, Central Council for Research in Homoeopathy, New Delhi; drcbnayak@gmail.com

11 - Central Council for Research in Homoeopathy, Hqrs; pramanikabhishek89@gmail.com

12 - Central Council for Research in Homoeopathy, Hqrs; arvinddayal@yahoo.com

13 - Central Council for Research in Homoeopathy, Hqrs; varanasiroja@gmail.com

*Correspondence author: varanasiroja@gmail.com

\begin{abstract}
Background Simple and mucopurulent chronic bronchitis (SMCB) is characterized by recurrent mucoid or mucopurulent expectoration in absence of localized suppurative disease. This observational open label study was undertaken to evaluate the effects of homeopathic medicine in SMCB. Methods 1902 patients were screened from 07 centres out of which 1305 were excluded. 597 patients were enrolled as per the inclusion and exclusion criteria. A total of 14 pre-defined homeopathic medicines were shortlisted for prescription after repertorizing the pathological symptoms of SMCB. Outcomes were assessed through chronic bronchitis symptom scale (CBSS) and FEV1/ FVC ratio with spirometry for over a period of two years. Appearance of any change (relief/ worse)/ status quo was immediately followed by placebo/ change in dilution/ change in remedy. Statistical analysis was done using SPSS version 20. Results: 532 patients were analyzed based on the intention to treat principle using last observation carry forward method. Mean CBS score reduced from $29.86 \pm 4.5$ at baseline to $12.33 \pm 7.6$ at completion of 2 years. Repeated measures ANOVA, at time points 0 (baseline), 3, 6, 9, $12,15,18,21$ and 24 months, showed significant reduction in CBS scores [Wilk's Lambda 0.104, F=564, df 524; p=00001]. The FEV1 and FEV1/FVC was maintained within normal limits. 86\% prescriptions included Lycopodium, Arsenicum album, Pulsatilla, Phosphorus, Stannum metallicum, Calcarea carbonica, Silicea, Bryonia alba. Conclusion: The result suggests effectiveness of homeopathic treatment in early years of SCMB patients. Controlled trials are warranted.
\end{abstract}

Keywords: chronic bronchitis, homeopathy, pre-defined medicines, early years

OPEN O ACCESS 


\section{Introduction}

Chronic obstructive pulmonary bronchitis (COPD) is a common, preventable and treatable disease characterized by persistent respiratory symptoms and airflow limitation due to airway and/or alveolar abnormalities, usually caused by significant exposure to noxious particles or gases [1]. It is a broad spectrum disease with chronic bronchitis (CB) at one end and emphysema at the other. Chronic bronchitis (CB) is a common but variable phenomenon defined as chronic productive cough for more than 3 months in each of 2 consecutive years [2,3]. It is a chronic progressive disease associated with exacerbations and remissions and often goes through three stages: simple chronic bronchitis, in which there is a recurrent increase in the volume of mucoid bronchial secretion sufficient to cause expectoration; chronic or recurrent muco-purulent bronchitis, when the sputum is persistent or intermittently purulent owing to secondary bacterial infection in the lung and chronic obstructive bronchitis, in which there is persistent, widespread narrowing of the intrapulmonary airways, at least on expiration, causing increased resistance to airflow [4].

The occurrence of CB in the general population has been documented to vary between $3 \%$ to $7 \%$ of healthy adults. However, it is estimated to be as high as 74\% among those diagnosed to have COPD. Many among those in the general population experiencing symptoms of chronic bronchitis may not have a definitive respiratory diagnosis [3]. Patients under the age of 50 years who are otherwise healthy and have $\mathrm{CB}$ are at a higher risk of morbidity and mortality when compared to healthy subjects [4]. The 'Indian Study of Asthma, Respiratory Symptoms and Chronic Bronchitis' (INSEARCH) on 85,105 men and 84,470 women from 12 urban and 11 rural sites reported the prevalence of CB to be $3.49 \%$ in adults > 35 years [5]. According to DALYs 2016, India , COPD, is leading cause of death next to ischemic heart disease [6].

If not treated, patients with chronic bronchitis symptoms had a threefold increased risk of developing new COPD compared to the asymptomatic population [3]. Each pharmacologic treatment regimen should be individualized and guided by the severity of symptoms, risk of exacerbations, side effects, co-morbidities, drug availability and costs, and the patient's response, preference, and ability to use various drug deliveries [1]. The primary aim of treatment for chronic bronchitis is to relieve symptoms, prevent complication and slow the progression of the disease. The classes of medications used are bronchodilators, antimuscarinic drugs, glucocorticoids, antibiotic therapy, and Phosphodiesterase-4 inhibitors. However, long term users will land into several complications/adverse effects [1].

In clinical practice, spirometry helps in the management of $\mathrm{CB}$ by documenting the extent of reversibility of airflow obstruction and provides valuable therapeutic information about the patient's responsiveness to inhaled bronchodilator therapy. A measured forced expiratory volume in one second $\left(\mathrm{FEV}_{1}\right)$ /forced vital capacity (FVC) i.e. FEV 1 /FVC ratio of less than 70 defines obstructive airways [1]. The airflow limitation measured though provides important information to the physician to enable optimization of management [7] but these pulmonary functions gradually deteriorate even when treated with bronchodilators, antibiotics and inhaled steroids.

A less expensive method as compared to modern medicine, is to treat the episodes as soon as they begin and to control the causative factors which exacerbate the condition [3]. Large cohort studies have shown that patients who chose to consult GPs certified in homeopathy used less antibiotics and antipyretic/anti-inflammatory drugs for URTI than those seen by GPs prescribing conventional medications [8]. 
WHO has acknowledged Homeopathy as second mainly applied and used system of medicine internationally [9]. Homeopathic treatment is associated with improvement of symptoms in a range of chronic and recurring pathologies $[10,11,12,13]$ and respiratory disorder $[8,14]$. A study on critically ill patients by Frass. et al [15] suggested that potentized potassium dichromate may help to decrease the amount of stringy tracheal secretions in COPD patients. Homeopathic treatment for respiratory diseases was associated with a significant reduction in the use and costs of conventional drugs [16]. Most real-world outcome studies in adults and children have shown benefits of homoeopathy in respiratory disorders [17]. However, no studies have been carried out on the patients in early years of simple and mucopurulent chronic bronchitis. Peters et al [18] suggested certain homeopathic medicines after repertorizing the disease symptoms of sinusitis but to be prescribed after individualization according to homeopathic principles. Similar pattern was adopted in this study too for arriving at 14 pre-defined medicines for SMCB. The present study was undertaken to evaluate the role of a group of 14 pre-defined homeopathic medicines in management of simple and mucopurulent chronic bronchitis.

\section{Objectives}

Primary objective was to evaluate the usefulness of homeopathic medicine(s) in the management of simple and mucopurulent chronic bronchitis (SMCB). Secondary objective was to evaluate the effect of homeopathic medicines in the spirometry $\left(\mathrm{FEV}_{1}\right.$ and $\left.\mathrm{FEV}_{1} / \mathrm{FVC}\right)$ findings.

\section{Material and methods}

Study design and Setting

This was a prospective observational study carried out during Oct. 2005 to Sept. 2010 at seven research centres under Central Council for Research in Homoeopathy namely: Dr DP Rastogi Central Research Institute, Noida, National Homeopathy Research Institute for Mental Health, Kottayam, Regional Research Institutes (Homoeopathy), Puri and Guwahati, Clinical Research Units, Puducherry, Chennai and Tirupati. The study protocol was prepared in accordance with Helsinki declaration [19] on human experimentation and necessary ethical clearance was obtained from the ethical committee of the Council and trial was registered at Clinical trials Registry-India (CTRI/2011/09/001994). The Investigators having an institutional qualification in Homoeopathy as per the regulations of Central Council of Homoeopathy, a statutory body for education and practice under Ministry of AYUSH, Govt. of India, and with more than 10 years of experience of homeopathic practice were responsible for prescribing homeopathic medicines, collecting data and for follow up for 2 years. All the investigators were trained in the protocol before initiation of the study. Doctors with speciality in Medicine were engaged as consultants at respective study centres for screening, enrolment and follow up of the study patients throughout. All patients gave written informed consent.

\section{Study Participants}

Inclusion criteria: Participants fulfilling the following inclusion criteria were enrolled in the study.

- Both genders and age between 20 and 50 years

- Patients presenting with chronic cough with excessive mucopurulent expectoration for at least 3 months in a year for more than two consecutive years

- Recurrent attacks of chronic cough usually in winter months which steadily increases in severity and duration.

- Patients who are not, on any other treatment, including homoeopathy

- Patients residing within approachable distance.

\section{OPEN ACCESS}


- $\mathrm{FEV}_{1}>80 \%$ predicted.

- Patients willing to participate in the study

- Patients who match the prescribing criteria for any of the 14 pre-defined medicines.

\section{Exclusion criteria}

- Patients suffering from central airflow obstruction, emphysema, cor-pulmonale, bronchial asthma, active pulmonary tuberculosis, broncho-pulmonary mycosis, acute bronchitis, pulmonary thromboembolism, pulmonary hypertension.

- Persons require hospitalization with other co-morbid conditions.

- Persons requiring oxygen therapy and hospitalization;

- $\mathrm{FEV}_{1}<80 \%$ predicted

- $\mathrm{FEV}_{1} / \mathrm{FVC}<0.7$

- Patients who did not match the prescribing criteria for any of the 14 pre-defined medicines.

\section{Homeopathic treatment}

The patients were screened in the Outpatient department (OPD)as per the inclusion and exclusion criteria mentioned above. A detailed case taking as per homeopathic methods was done after patient fulfilled the inclusion criteria. Those who were not fulfilling the inclusion criteria, were excluded and treated in the General OPD.

\section{Selection of pre-defined trial medicines, first prescription and follow up}

The selection of pre-defined trial medicines was done by repertorizing the 21 disease symptoms of CB (Table 1). Repertorisation was done using the Complete Repertory from CARA Professional software [20] (Table 2). Considering the fact that the study pertains to $C B$, the drugs given in the first grade ( 3 points) followed by those in the second grade ( 2 points) mentioned against the rubric 'chronic cough' were short-listed through an elimination method. The 14 pre-defined medicines identified in the order of their high score were, Stannum metallicum, Arsenicum album, Silicea, Phosphorus, Lycopodium, Pulsatilla nigricans, Calcarea carbonica, Sulphur, Hepar sulphur, Bryonia alba, Ipecacuanha, Antimonium tartaricum, Carbo vegetalis and Spongia tosta. These medicines were procured from M/S Sharda Boiron Laboratory Pvt. Ltd. Sahibabad, (U.P.) India.

Selection of the specific medicine for each patient was done on basis of the highest score on repertorization of the presenting signs and symptoms of the patient which was further guided by the characteristic mental/emotional and physical attributes of the patient, finally verified by the Materia Medica. The investigator was free to change prescription up to three times including first prescription. However, if the selected medicine was out of the group of pre-defined trial medicines then the patient was not included in the study but was treated in the general OPD. Throughout the study period each enrolled patient was prescribed one of these trial medicines only.

The prescription of the selected medicine started with $30 \mathrm{CH}$ potency, in a single dose (four pills of globule No. 30) followed by placebo (four pills of unmedicated globules No. 30), daily. Follow up was weekly for the $1^{\text {st }}$ month, fortnightly for the next 2 months and monthly for the remaining period until completion of 24 months. On each of these visits, clinical assessment was done by the investigator. Spirometry was performed at the time of enrollment, at every $3^{\text {rd }}$ month till 24 months.

Selection of the specific medicine for each patient was done on basis of the highest score on repertorization of the presenting signs and symptoms of the patient which was further guided by the characteristic mental/emotional and physical attributes of the patient, finally verified by the Materia Medica. The investigator was free to change prescription up to three times including first 
prescription. However, if the selected medicine was out of the group of pre-defined trial medicines then the patient was not included in the study but was treated in the general OPD. Throughout the study period each enrolled patient was prescribed one of these trial medicines only.

Table1 - List of 21 symptoms of chronic bronchitis considered for repertorization

\begin{tabular}{|l|l|}
\hline 1.Chest; inflammation; Bronchial tubes & 2.Cough; chronic \\
\hline 3.Expectoration; copious; chronically & 4.Cough, winter \\
\hline $\begin{array}{l}\text { 5.Expectoration; constant, almost day and } \\
\text { evening }\end{array}$ & 6.Expectoration; copious; paroxysmal cough, after \\
\hline 7.Expectoration; frequent & 8.Respiration; difficult; cough; with \\
\hline 9.Expectoration; mucous & 10.Expectoration; mucous; translucent \\
\hline 11.Expectoration; frothy & 12.Expectoration; easy \\
\hline 13.Expectoration; transparent & 14.Expectoration, white \\
\hline 15.Expectoration; purulent & 16.Expectoration; difficult \\
\hline 17.Expectoration; yellow & 18.Expectoration; thick \\
\hline 19.Expectoration; lumpy & 20.Expectoration; balls, in shape of \\
\hline 21.Respiration; difficult; exertion, after & \\
\hline
\end{tabular}

The prescription of the selected medicine started with $30 \mathrm{CH}$ potency, in a single dose (four pills of globule No. 30) followed by placebo (four pills of unmedicated globules No. 30), daily. Follow up was weekly for the $1^{\text {st }}$ month, fortnightly for the next 2 months and monthly for the remaining period until completion of 24 months. On each of these visits, clinical assessment was done by the investigator. Spirometry was performed at the time of enrollment, at every $3^{\text {rd }}$ month till 24 months.

In case there was no perceptible change after one week of administration of the indicated medicine, one more dose of the same medicine was repeated in higher potency. If no improvement was found even after adequate repetition of the medicine in higher potencies, the investigator was allowed to change the prescription. All patients were advised for avoidance of smoking, dust and air pollution. Patients were advised for intake of nutritious diet and to do routine physical exercise as a part of general management. Patients were free to report at any time during adverse events or emergency situations. Any change (improvement/deterioration) triggered by administration of placebo or change in potency (from $30 \mathrm{C}$ to $200 \mathrm{C}$ or $1 \mathrm{M}$ ) or change in remedy was managed by following the guidelines of Hahnemann [21] and Kent [22]. The guidelines were:

i. $\quad$ If improvement continues (score is reduced) $\rightarrow$ Placebo to continue.

ii. If improvement stops (same score) $\rightarrow$ repeat the medicine (first prescription) in the same potency. 
iii. If no further amelioration occurs even after medicine is given in same potency or improvement lasts for a very short period $\rightarrow$ to give higher potency of same medicine.

iv. If amelioration of presenting complaints is accompanied by appearance of old symptoms $\rightarrow$ to continue placebo, till the improvement continues.

v. If old symptoms come back to stay $\rightarrow$ same medicine in same potency to be repeated and then followed as in (iii) above. In case there was no perceptible improvement after adequate repetition of medicine in different potencies, change of medicine was to be considered.

In case of acute exacerbation of CB or any other acute disease condition, the medicine selected was either a continuation of the pre-selected medicine, or one of the better indicated trial medicines. This medicine was prescribed repeatedly as per intensity of the acute exacerbation.

\section{Outcome assessment}

The symptoms and signs of the enrolled patients were rated by the investigators using Chronic Bronchitis Symptom Scale (CBSS) at baseline and follow-up visits at every 3 months up to 2 years (Table 3). This scale was developed by the Council and approved by a group of experts for its content and consistency to assess the symptoms of enrolled patients. Evaluation of each subjective symptom in terms of score was done by attributing "0" score to no symptom, and 1, 2, 3, 4, ranking was made for different degrees of intensity of each symptom. The intensity of the disease at baseline was classified and graded into 3 categories. Mild (CBS score 10 to 15); Moderate (CBS score 16 to 31) and Severe (CBS score 32 to 40 ). The $\mathrm{FEV}_{1}$ and $\mathrm{FEV}_{1} / \mathrm{FVC}$ ratio was also estimated at baseline and at time points of $3,6,9,12,15,18,21$, and 24 months.

Further outcome in terms of percentage was also calculated as follows:

$$
\text { Outcome }=\frac{\text { Baseline score }- \text { Score at end }}{\text { Baseline score }} \times 100
$$

Changes were graded as:

- Marked improvement ( $75 \%$ to $<100 \%)$,

- Moderate improvement (50\% to $<75 \%)$,

- Mild improvement (25\% to $<50 \%)$,

- Not significant improvement $(<25 \%)$,

- Static (no change), and

- worse (increase in CBSS).

\section{Statistical analysis}

Statistical analysis was done using IBM Statistical Package for Social Sciences, version 20, based on intention to treat approach: The last value for those patients who dropped out, was carried forward for analysis. Data were analyzed using parametric/non-parametric statistical tools depending on the nature of the data. Therefore, dispersion is represented with mean \pm SD, mean change (SE) with $95 \%$ CI. Repeated measure of ANOVA was used to assess the outcome at different time points up to 24 months. Standardized effects (d) were calculated by dividing Treatment effects as estimated above by baseline Standard deviations. They were classified: as $|\mathrm{d}|>0.8$, large; $|\mathrm{d}|>0.5$, medium; $|\mathrm{d}|>0.2$, small [23]. P value $<0.05$ was considered as significant. 
Table 2 - Repertorization chart (using complete repertory)

\begin{tabular}{|c|c|c|c|c|c|c|c|c|c|c|c|c|c|c|c|c|c|c|}
\hline Drug & Stann & Ars & Sil & Phos & Lyc & Puls & Calc & Sulph & Нер & Ip & Bry & Caust & Ant-t & Carb-v & Dulc & Spong & Dros & Chin \\
\hline Score & $\begin{array}{c}40 / \\
16\end{array}$ & $\begin{array}{c}36 \\
/ \\
15\end{array}$ & $\begin{array}{c}35 \\
/ \\
17\end{array}$ & $\begin{array}{c}34 / \\
14\end{array}$ & $\begin{array}{c}29 \\
/ \\
14\end{array}$ & $\begin{array}{c}29 / \\
14\end{array}$ & $\begin{array}{c}25 / \\
11\end{array}$ & $\begin{array}{c}24 / \\
18\end{array}$ & $\begin{array}{c}22 / \\
11\end{array}$ & $\begin{array}{c}20 \\
/ 1 \\
2\end{array}$ & $\begin{array}{c}20 \\
/ \\
11\end{array}$ & $\begin{array}{c}20 / \\
9\end{array}$ & $\begin{array}{c}19 / \\
12\end{array}$ & $\begin{array}{c}19 / \\
11\end{array}$ & $\begin{array}{c}17 / \\
10\end{array}$ & $\begin{array}{c}17 / \\
9\end{array}$ & $\begin{array}{c}17 / \\
8\end{array}$ & $\begin{array}{c}16 / \\
8\end{array}$ \\
\hline 01 & 3 & 3 & 3 & 3 & 3 & 3 & 2 & 2 & 3 & 3 & 3 & 2 & 3 & 2 & 2 & 3 & 3 & 3 \\
\hline 02 & 0 & 0 & 1 & 2 & 1 & 1 & 0 & 1 & 0 & 0 & 0 & 0 & 2 & 0 & 1 & 2 & 2 & 0 \\
\hline 03 & 3 & 3 & 3 & 3 & 1 & 0 & 3 & 3 & 0 & 0 & 2 & 3 & 0 & 3 & 3 & 0 & 0 & 0 \\
\hline 04 & 2 & 1 & 0 & 0 & 0 & 0 & 0 & 0 & 0 & 1 & 1 & 0 & 1 & 0 & 1 & 0 & 0 & 0 \\
\hline 05 & 0 & 0 & 0 & 0 & 0 & 0 & 0 & 0 & 0 & 0 & 0 & 0 & 0 & 0 & 0 & 0 & 0 & 0 \\
\hline 06 & 0 & 0 & 0 & 0 & 0 & 0 & 0 & 1 & 0 & 0 & 0 & 0 & 0 & 0 & 0 & 0 & 0 & 0 \\
\hline 07 & 2 & 0 & 1 & 0 & 1 & 2 & 0 & 1 & 1 & 0 & 0 & 0 & 0 & 0 & 0 & 0 & 0 & 0 \\
\hline 08 & 3 & 3 & 2 & 3 & 2 & 0 & 1 & 1 & 2 & 3 & 1 & 2 & 3 & 2 & 0 & 1 & 3 & 1 \\
\hline 09 & 3 & 3 & 3 & 3 & 3 & 3 & 3 & 1 & 3 & 1 & 3 & 3 & 2 & 2 & 3 & 2 & 3 & 3 \\
\hline 10 & 0 & 3 & 1 & 0 & 0 & 0 & 0 & 0 & 0 & 0 & 0 & 0 & 0 & 0 & 0 & 0 & 0 & 3 \\
\hline 11 & 0 & 3 & 1 & 2 & 0 & 2 & 1 & 1 & 1 & 1 & 1 & 0 & 1 & 0 & 0 & 0 & 1 & 0 \\
\hline 12 & 3 & 0 & 1 & 0 & 0 & 2 & 0 & 1 & 1 & 1 & 0 & 0 & 1 & 1 & 1 & 0 & 0 & 0 \\
\hline 13 & 2 & 2 & 2 & 3 & 0 & 1 & 0 & 1 & 0 & 0 & 1 & 2 & 1 & 0 & 0 & 0 & 0 & 1 \\
\hline 14 & 2 & 2 & 1 & 3 & 3 & 2 & 2 & 2 & 0 & 1 & 1 & 2 & 1 & 2 & 1 & 2 & 0 & 1 \\
\hline 15 & 2 & 2 & 3 & 3 & 3 & 2 & 3 & 1 & 1 & 1 & 1 & 0 & 2 & 1 & 1 & 0 & 2 & 3 \\
\hline 16 & 3 & 2 & 0 & 2 & 2 & 3 & 2 & 1 & 2 & 3 & 1 & 3 & 1 & 0 & 2 & 1 & 1 & 1 \\
\hline 17 & 3 & 2 & 3 & 3 & 3 & 3 & 3 & 2 & 3 & 1 & 2 & 1 & 0 & 2 & 0 & 2 & 2 & 0 \\
\hline 18 & 2 & 2 & 3 & 1 & 2 & 2 & 2 & 1 & 3 & 1 & 1 & 2 & 1 & 1 & 2 & 0 & 0 & 0 \\
\hline 19 & 2 & 2 & 3 & 1 & 1 & 1 & 0 & 1 & 2 & 0 & 1 & 0 & 0 & 1 & 0 & 1 & 0 & 0 \\
\hline 20 & 3 & 0 & 2 & 0 & 1 & 0 & 0 & 1 & 0 & 0 & 0 & 0 & 0 & 0 & 0 & 0 & 0 & 0 \\
\hline 21 & 2 & 3 & 2 & 2 & 3 & 2 & 3 & 2 & 0 & 3 & 0 & 0 & 0 & 2 & 0 & 3 & 0 & 0 \\
\hline
\end{tabular}


Table 3 - The chronic bronchitis symptom scale(CBSS)

\begin{tabular}{|c|c|c|c|c|c|}
\hline \multirow[t]{2}{*}{ Symptoms } & \multicolumn{5}{|c|}{ Score } \\
\hline & 0 & 1 & 2 & 3 & 4 \\
\hline Chronic Cough & Absent & & Present & & \\
\hline Severity & & $\begin{array}{c}\text { Mild } \\
\text { (irritating) }\end{array}$ & $\begin{array}{c}\text { Moderate } \\
\text { (distressing) }\end{array}$ & & $\begin{array}{c}\text { Severe } \\
\text { (spasmodic) }\end{array}$ \\
\hline $\begin{array}{c}\text { Paroxysms } \\
\text { [duration] }\end{array}$ & Nil & $\begin{array}{l}1 \text { hour to less } \\
\text { than } 6 \text { hours }\end{array}$ & $\begin{array}{l}6 \text { hours to less } \\
\text { than } 12 \text { hours }\end{array}$ & $\begin{array}{l}12 \text { hours to less } \\
\text { than } 18 \text { hours }\end{array}$ & $\begin{array}{l}18 \text { hours to less } \\
\text { than } 24 \text { hours }\end{array}$ \\
\hline \multicolumn{6}{|l|}{ Expectoration } \\
\hline Expectoration & Absent & $1 \mathrm{hr}$. to $6 \mathrm{hrs}$. & $6 \mathrm{hrs}$. to $12 \mathrm{hrs}$. & $\begin{array}{c}12 \text { hrs. to } 18 \\
\text { hrs. }\end{array}$ & $18 \mathrm{hrs}$. to $24 \mathrm{hrs}$. \\
\hline Difficulty in raising & & Easy & & Difficult & \\
\hline Quantity & & Scanty & & Copious & \\
\hline Quality & & Thin & & Thick & $\begin{array}{l}\text { Lumpy / in shape } \\
\text { of balls }\end{array}$ \\
\hline Quality-1 & & Mucoid & Frothy & & Purulent \\
\hline Quality-2 & & $\begin{array}{c}\text { Transparent / } \\
\text { Translucent }\end{array}$ & White & Yellow & Greenish \\
\hline Difficult respiration & Absent & & Present & & \\
\hline & Absent & Heavy exertion & & Mild exertion & With cough \\
\hline Crackles & Absent & 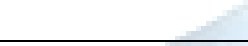 & Present & & \\
\hline Total & & & 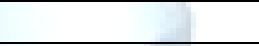 & & \\
\hline \multicolumn{6}{|c|}{ Total of symptom score: ----[10-40] } \\
\hline Intensity of & ase - M & D: 10 to 15 & DERATE: 16 to 31 & SEVE & 32 to 40 \\
\hline
\end{tabular}

\section{Results}

A total of 597 patients were enrolled in the study from seven centres . Out of these, 109 patients were lost to follow up at different time points. Data of 65 patients who dropped out could not be traced. Therefore this paper reflects the ITT analysis of 532 patients suffering from SMCB. Figure 1 shows the flow of patients throughout the study. The study population $(n=532)$ consisted of 321 males, 211 females with average age of 34.1 years \pm 8.6 years. Out of 321 males, $60(11 \%)$ were smokers. The baseline characteristics of the patients are given in table 4.

\section{Figure 1 - Flow of patients throughout the study}

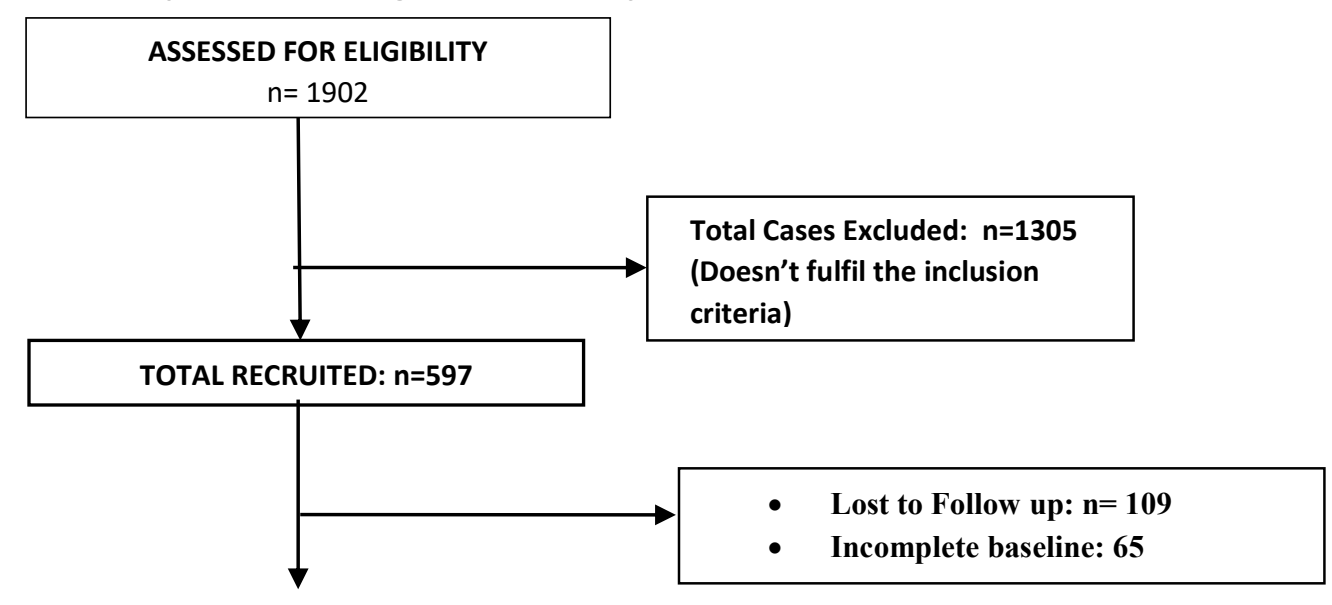

ANALYZED ITT: $\mathbf{N}=532$ 
Table 4 - Baseline information of 532 analyzed patients

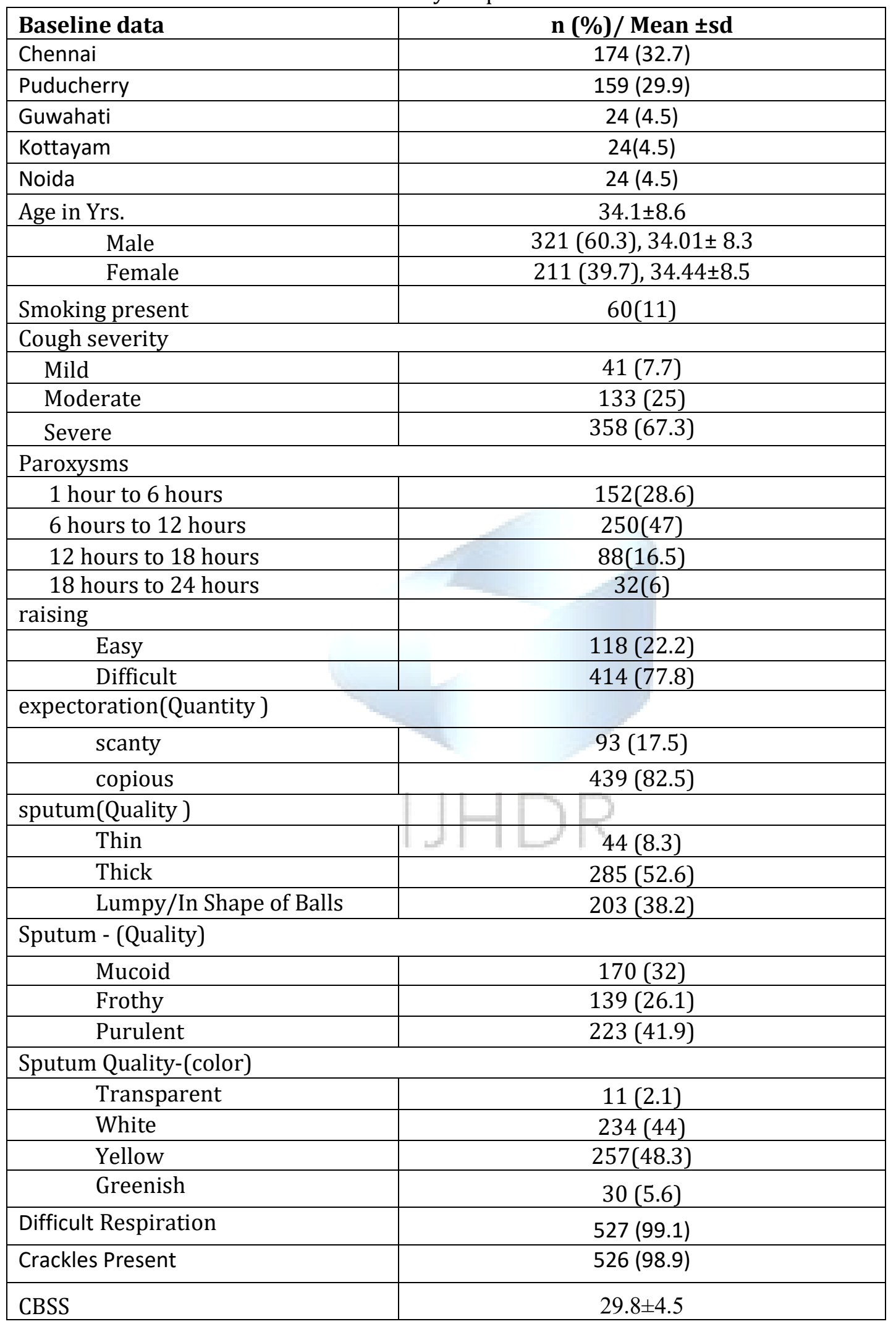




\begin{tabular}{|c|c|}
\hline CBSS gradation & \\
\hline Mild & $1(0.2)$ \\
\hline Moderate & $297(55.8)$ \\
\hline Severe & $234(44)$ \\
\hline FEV1 & $94.12 \pm 13.6$ \\
\hline FEV1/FVC ratio & $1.64 \pm 0.92$ \\
\hline
\end{tabular}

\section{Effect on SMCB symptoms}

The mean CBS score at baseline was $29.86 \pm 4.5$ and reduced to $12.33 \pm 7.6$ at completion of 2 years. Repeated measures ANOVA, during the two-year treatment period, at time points 0 (baseline), 3, 6, 9, $12,15,18,21$ and 24 months, showed significant reduction in CBS scores [Wilk's Lambda 0.104, $\mathrm{F}=564$, df 524; $\mathrm{p}=00001]$. Figure 2 shows the trend in scores at different time points. Post hoc paired $t$ test also showed significant difference at 24 months compared to baseline. The Effect size as mentioned by cohen was calculated. There is a significant effect of homeopathic medicines on SMCB patients at 3 months ( $\mathrm{Mdn}=4, \mathrm{Z}=20.2, \mathrm{r}=0.6, \mathrm{P}<0.001$ ) which was maintained up to $24^{\text {th }}$ month $(M d n=3, Z=20.32, r=0.6, P<0.001$ (Table 5). It was observed that homeopathic treatment based on individualization has large effect size which was maintained upto $24^{\text {th }}$ month of treatment. Most of the patients belonged to moderate $(55.8 \%)$ and severe intensity (44\%) of CB as per the CBSS at baseline. Overall, marked improvement was observed in 176 patients $(33.1 \%)$, moderate improvement in 213 patients (40\%), mild improvement in 63 patients $(11.8 \%)$, no significant improvement in 52 patients $(9.8 \%)$, status quo in $20(3.8 \%)$, and worsening in $8(1.5 \%)$ patients. The category wise outcome as per the CBS score is given in figure 3 .

Figure 2 - Trend line showing mean CBS scores at different time points with 95\% Error bars

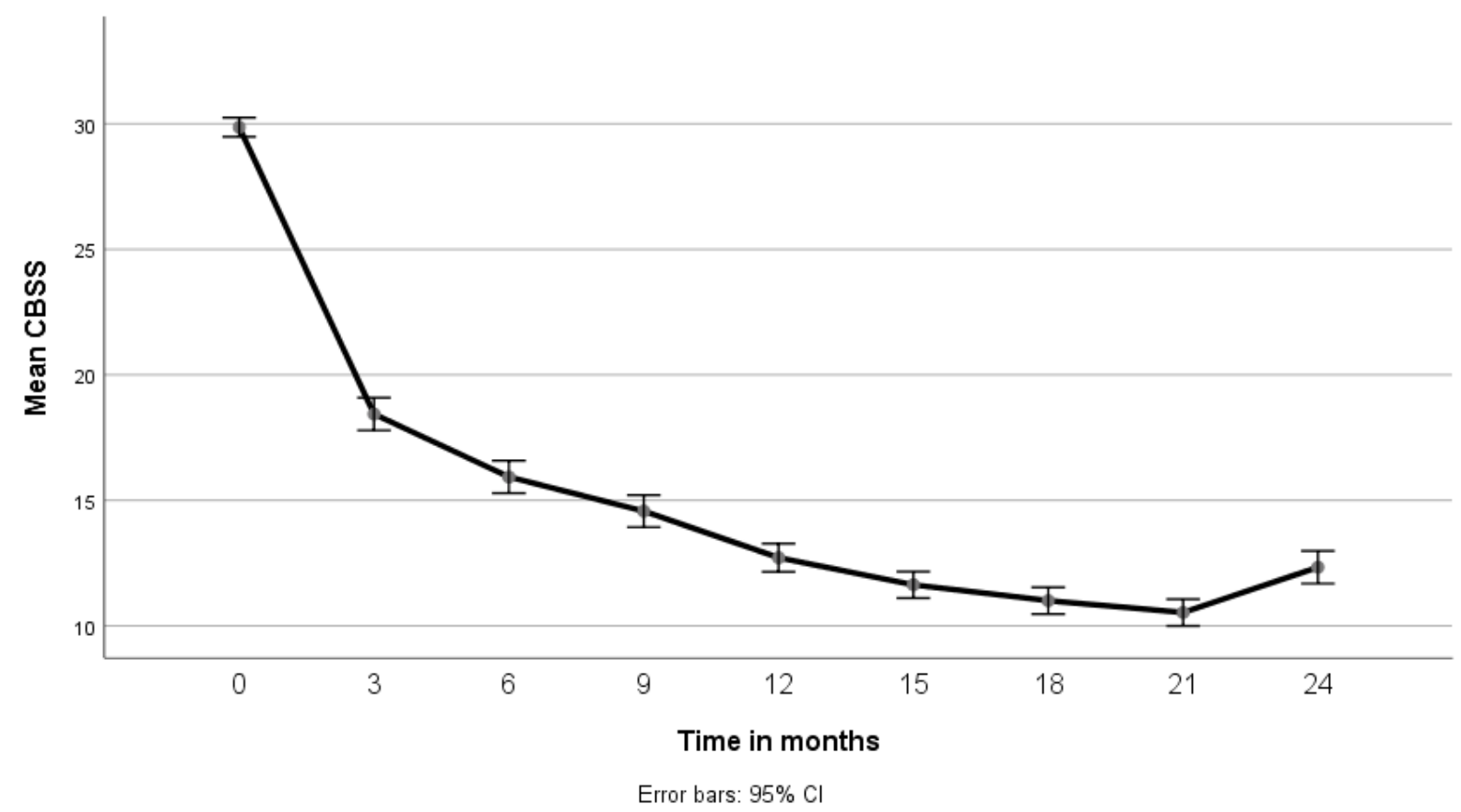


International Journal of High Dilution Research 2019; 18(3-4):47-62

Available online at www.highdilution.org

Table 5 - Outcome at different time points of 24 months

\begin{tabular}{|c|c|c|c|c|c|c|c|c|c|}
\hline Variable & $\begin{array}{c}\text { At baseline } \\
(0 \text { month })\end{array}$ & 3 months & 6 months & 12 months & 24 months & 0-3 & $0-6$ & 0-12 & $0-24$ \\
\hline & & \multicolumn{4}{|c|}{ Mean change (SE);95\% CI } & \multicolumn{4}{|c|}{ Cohen's d } \\
\hline Total CBSS & $29.9 \pm 4.5$ & $11.4(0.3) ; 10-8,12.0$ & $13.9(0.3) ; 13.2,14.5$ & $17.1(0.3) ; 16.5,17.7$ & $17.5(0.3) ; 16.8,18.2$ & 1.84 & 2.24 & 3.04 & 2.81 \\
\hline - $\quad$ Mild $(\mathrm{n}=1)^{*}$ & $15.0 \pm 0.0$ & - & - & - & - & & & & - \\
\hline - Moderate $(n=297)$ & $26.9 \pm 3.6$ & $\begin{array}{c}10.8(0.4) ; 10.0 \\
11.5\end{array}$ & $\begin{array}{c}12.8(0.4) ; 12.0 \\
13.7\end{array}$ & $15.6(0.4) ; 14.8,16.4$ & $15.9(0.4) ; 15.1,16.7$ & 2.10 & 2.39 & 3.23 & 3.07 \\
\hline - $\quad$ Severe $(n=234)$ & $33.7 \pm 1.6$ & $\begin{array}{c}12.3(0.5) ; 11.3 \\
13.4\end{array}$ & $\begin{array}{c}15.4(0.5) ; 14.3 \\
16.4\end{array}$ & $19.2(0.5) ; 18.3,20.1$ & $19.7(0.6) ; 18.6,20.8$ & 2.08 & 2.65 & 3.73 & 3.17 \\
\hline $\mathrm{FEV}_{1}$ & $94.13 \pm 13.61$ & $1.6(0.5) ; 0.6,2.6$ & $2.3(0.7) ; 1.0,3.6$ & $0.5(0.7) ;-0.9,1.8$ & $-2.5(0.8) ;-4.0,-1.0$ & 0.11 & 0.14 & 0.03 & 0.16 \\
\hline $\mathrm{FEV}_{1} / \mathrm{FVC}$ ratio & $1.65 \pm 0.93$ & $\begin{array}{c}0.01(0.004) ;- \\
0.0003,0.02\end{array}$ & $\begin{array}{c}-0.006(0.02) ;- \\
0.04,0.02\end{array}$ & $\begin{array}{c}-0.05(0.02) ;-0.09,- \\
0.01\end{array}$ & $\begin{array}{c}-0.07(0.01) ;-0.10,- \\
0.04\end{array}$ & 0.011 & 0.010 & 0.050 & 0.07 \\
\hline
\end{tabular}

*only one patient was in mild category, so no analysis could be performed.

Figure 3 - Outcome of patients according to severity as per the gradation of total CBS score.

OPEN

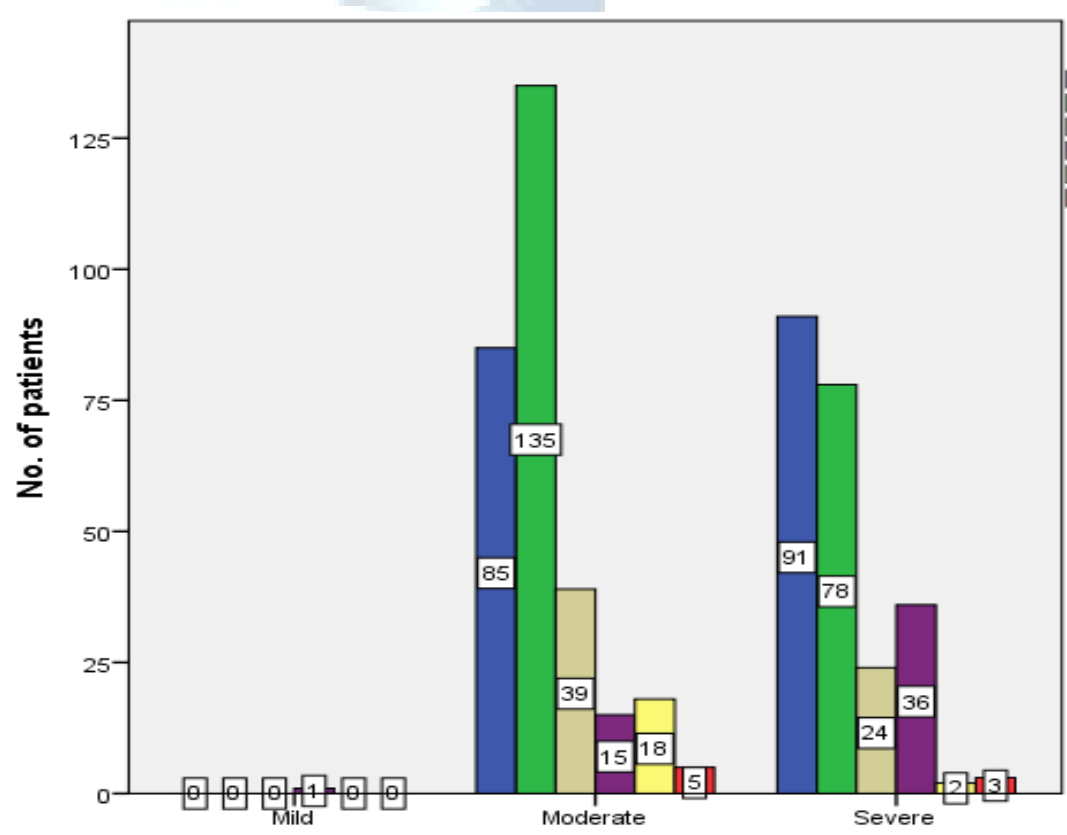

Category according to CBS score

Overall Outcome Marked improvement Moderate improvement Improvement not significant No change/Static $\square$ worsened 
Effect on spirometry test

The mean $\mathrm{FEV}_{1} / \mathrm{FVC}$ of $1.6 \pm 0.9$ at baseline was maintained at time points $3,6,9,12,15,18,21$ and 24 months respectively. A scattered plot drawn depicting difference of total CBS scores (0 -24 months) and difference of $\mathrm{FEV}_{1}, \mathrm{FEV}_{1} / \mathrm{FVC}$ (24-0 months) showed statistically significant positive correlation (Figure 4,5 ). TheFEV ${ }_{1}$ and $\mathrm{FEV}_{1} / \mathrm{FVC}$ was maintained within normal limits throughout the study period showing effect of homeopathic medicines in SMCB.

Figure 4 - Correlation CBS score and $\mathrm{FEV}_{1}$

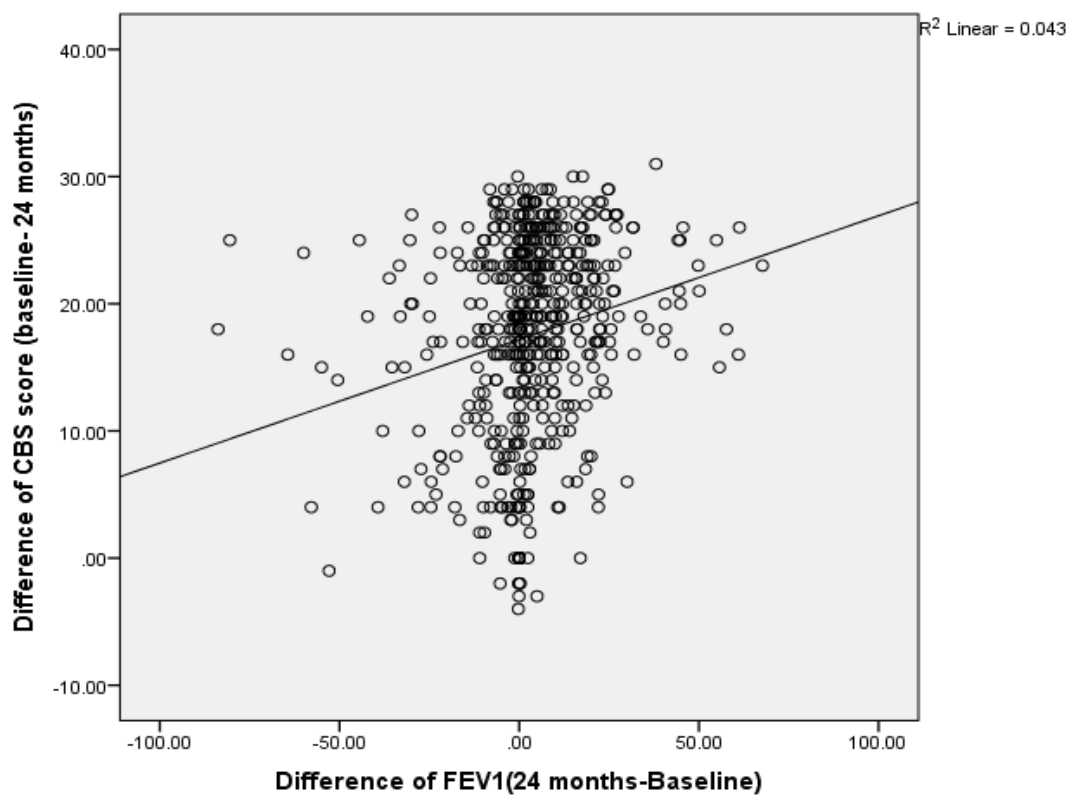

Figure 5 - Correlation CBS score and $\mathrm{FEV}_{1} / \mathrm{FVC}$

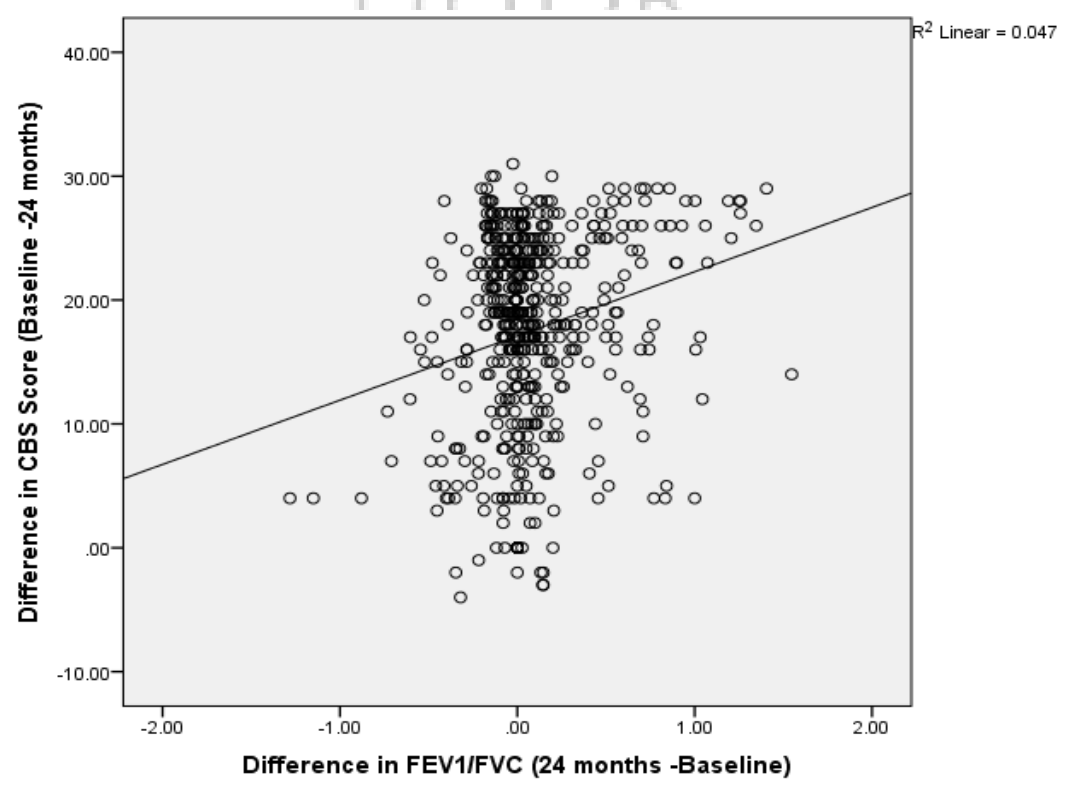


Homeoapthic medicines prescribed

The 14 pre defined medicines, which were prescribed as per the descending order are: Lycopodium $(\mathrm{n}=168 ; 31.6 \%)$, Arsenicum album ( $n=93 ; 17.5 \%)$, Pulsatilla $(n=83 ; 15.6 \%)$, Phosphorus $(\mathrm{n}=53$; $10.05 \%)$, Stannum metallicum ( $n=41 ; 7.7 \%)$, Calcarea carbonica( $n=24 ; 4.5 \%)$, Silicea( $n=19 ; 3.6 \%)$, Bryonia ( $n=12 ; 2.3 \%)$, Antimonium tartaricum ( $n=9 ; 1.7 \%)$, Sulphur $(n=8 ; 1.5 \%)$, Hepar sulph.(n=7; $1.3 \%)$, Spongia $(n=7 ; 1.3 \%)$, Ipecacuanha $(n=6 ; 1.1 \%)$, Carbo vegetabilis $(n=2 ; 0.4 \%)$.

\section{Discussion}

This is a cohort study with two years follow up wherein patients in early years of chronic bronchitis without any pathological changes i.e. changes in the $\mathrm{FEV}_{1}$ and $\mathrm{FEV}_{1} / \mathrm{FVC}$ ratio, were evaluated to assess symptomatic improvement with pre-defined homeopathic medicines. Data of 532 patients with SMCB was analyzed. Using the 14 pre-defined homeopathic medicines, the results showed a positive role of homeopathic medicines in the management of symptoms of SMCB and maintaining the levels of $\mathrm{FEV}_{1 /} \mathrm{FVC}$ within normal limits. The mean CBS score of 29.75 was reduced to 12.3 during 24 months of treatment.

The males were predominantly affected than the females. This is consistent with epidemiological data on chronic bronchitis showing predilection in males compared to females [24].

$86 \%$ of the prescriptions were covered by the 6 high scoring trial medicines Lycopodium, Arsenicum album, Pulsatilla, Phosphorus, Stannum metallicum, and Calcarea carbonica. Frass et al [17] had conducted a study on 50 critically ill patients of COPD with a history of tobacco use. Their primary outcome was on the amount of tenacious, stringy tracheal secretions. The intervention group was given Potassium dichromate 30C (Kali bichromicum 30C). The amount of tracheal secretions was reduced significantly in intervention group $(\mathrm{p}<0.0001)$. Extubation could be performed significantly earlier in group 1 ( $\mathrm{p}<0.0001)$. Further, in the said study length of stay was significantly shorter in intervention group ( $4.20 \pm 1.61$ days vs $7.68 \pm 3.60$ days, $\mathrm{p}<0.0001$ [mean \pm SD]). However, Kali bichromicum was not prescribed in our study as this drug was not enlisted under 14 pre- defined medicines.

There is still no consensus definition of "early" COPD. Therefore, the treatment of early COPD with inhalers is also questionable. Enright in his paper [25] quoted that "There is limited and conflicting evidence of health benefits from initiation of inhaled bronchodilators (anticholinergics or long-acting beta-agonists) in symptomatic patients with $\mathrm{FEV}_{1}$ between $60 \%-80 \%$ predicted as documented by spirometry". However, GOLD statement [1] clearly mentions that use of short acting bronchodilators is not recommended. Further the same statement also conveys that there is no conclusive clinical trial evidence that any existing medications for COPD modify the long-term decline in lung function. Homeopathic intervention if used as per the outcomes observed in this study may help in managing the symptoms of SMCB in its early years and with no side effects.

In the absence of control arm, there is always chance of over-estimation of treatment effect sizes. This may be attributable to placebo effect; regression effect to the mean. Another, limitation was the absence of pre-validated scale to measure the improvement. We developed a scoring scale (CBSS), however, its validity and reliability remained untested. Though our study has several biases, it has

OPEN OCCESS 
scope too. This present study describes patients with varying lifestyles and socio-economic background, with high degree of external validity that extends to usual medical practice. These results certainly contribute to the growing evidence that homeopathy is a safe and beneficial treatment strategy for chronic diseases in primary care settings.

\section{Conclusion}

The results of this study show beneficial effects of homeopathic medicines using a treatment plan with 14 pre-selected homeopathic medicines in patients of simple and muco-purulent chronic bronchitis. There was a positive correlation between CBS score and spirometry findings up to two years. Further studies with controlled study designs under different setting are warranted.

\section{Financial support: Central Council for Research in Homoeopathy}

Conflict of interest - We declare no conflict of interest.

\section{Acknowledgement}

The authors acknowledge Dr Alok Kumar, Director General In-charge for his valuable support. The authors also acknowledge all the program officers of the Institutes/ Units for their administrative support, medicine specialists, engaged as consultants for screening, enrollment and follow up of the patients, and finally the patients for their endeavor to make this study successful.

\section{References}

[1] GOLD. Global Strategy for the Diagnosis, Management and Prevention of COPD, Global Initiative for Chronic Obstructive Lung Disease (GOLD); 2018 (Accessed Sept 17, 2019). Available at : https://goldcopd.org/wp-content/uploads/2018/02/WMS-GOLD-2018-FebFinal-to-print-v2.pdf

[2] Kim V, Criner J G. Chronic Bronchitis and Chronic Obstructive Pulmonary Disease. Am J RespirCrit Care Med. 2013; 187(3): 228-237.

[3] Widysanto A, Mathew G. Chronic Bronchitis. [Updated 2019 Mar 13]. In: Stat Pearls [Internet]. Treasure Island (FL): StatPearls Publishing; 2019 Jan-. Available from: https://www.ncbi.nlm.nih.gov/books/NBK482437.

[4] Anonymus. Natural history of chronic bronchitis. Br Med J. 1976 ;1(6021):1297-8.

[5] Jindal SK, Aggarwal AN, Gupta D, Agarwal R, Kumar R, Kaur T, et al. Indian study on epidemiology of asthma, respiratory symptoms and chronic bronchitis in adults (INSEARCH) Int J Tuberc Lung Dis. 2012;16:1270-7.

[6] Govt. of India. India: Health of the Nation's States The India State-Level Disease Burden Initiative [internet], accessed on 25 Apr 2018]. Available at 
http://www.healthdata.org/sites/default/files/files/policy_report/2017/India_Health_of_t he_Nation\%27s_States_Report_2017.pdf

[7] Lange P, Halpin D M, O'Donnell D E, MacNee W. Diagnosis, assessment, and phenotyping of COPD: beyond FEV1Int J Chron Obstruct Pulmon Dis. 2016; 11(Spec Iss): 3-12.

[8] Bensouda LG, Bégaud B, Rossignol M, Bernard A, Lert F, Rouillon F, et al. Management of Upper Respiratory Tract Infections by Different Medical Practices, Including Homeopathy, and Consumption of Antibiotics in Primary Care: The EPI3 Cohort Study in France 20072008 PLoS One. 2014; 9(3): e89990.

[9] Tierney, Macphee, Maxine.A. Papadakis.Current Medical Diagnosis \& Treatment 44th edition 2005. McGraw-Hill Companies Inc USA.pg.1716.

[10] Wassenhoven Van M, Ives G. An observational study of patients receiving homeopathic treatment. Homeopathy 2004; 93: 3-11.

[11] Rossi E, Endrizzi C, Panozzo MA, Bianchi A, Da Frè M. Homeopathy in the public health system: a seven-year observational study at Lucca Hospital (Italy). Homeopathy. 2009 ; 98(3):142-8.

[12] Spence DS, Thompson EA, Barron SJ. Homoeopathic treatment for chronic disease: A 6year, university-Hospital Outpatient observational study. The Journal of Alternative and complementary medicine 2005; 11(5):793-798.

[13] Witt C, Keil T, Selim D, Roll S, Vance W, Wegscheider K, Willich S N. Outcome and costs of homoeopathic and conventional treatment strategies: A comparative cohort study in patients with chronic disorders. Complementary Therapies in Medicine 2005; 13: 79-86.

[14] Haidvogl M, Riley DS, Marianne H et al. Homeopathic and conventional treatment for acute respiratory and ear complaints: A comparative study on outcome in the primary care setting; BMC Complementary and Alternative Medicine; 2007. 7:7 [doi:10.1186/1472-68827-7].

[15] Frass M, Dielacher C, Linkesch M, Endler C, Muchitsch I, Schuster E, Kaye A. Influence of potassium dichromate on tracheal secretions in critically ill patients. Chest. 2005 ;127(3):936-41.

[16] Elio R, Lara C., Cristina E, Danila G. Cost-benefit evaluation of homeopathic versus conventional therapy in respiratory diseases. Homeopathy. 2009;98(1):2-10.

[17] Riley D, Fischer M, Singh B, Haidvogl M, Heger M. Homeopathy and conventional medicine: an outcomes study comparing effectiveness in a primary care setting Journal of Alternative Complementary Medicine 2001; 7: 149-159.

[18] Peters D, Taylor Reilly D, Feruguson A, McIntyre M. How I would treat chronic sinusitis. Complement Ther Med 1993; 1: 81-87.

[19] World Medical Association Declaration of Helsinki -Ethical Principles for Medical Research Involving Human Subjects. Available from URL: http://www.who.int/bulletin/archives/79(4)373.pdf 
[20] Witko D. CARA Professional (C) 1997, London, Miccant Ltd. Revised programme by John Stevenson 1999.

[21] Hahnemann, S. Organon of Medicine; 6th sedition; New Delhi; B Jain Publishers: 1997.

[22] Kent JT. Lectures on Homoeopathic Philosophy. Reprint 4th edn.. B Jain Publishers (P) Ltd. New Delhi;1997.

[23] Cohen J. Statistical Power Analysis for the Behavioural Sciences.2nd ed. USA: Lawrence Erlbaum Associates Publishers; 1988.

[24] Mejza F, Gnatiuc L A. Buist SWM, Lamprecht B, Obaseki DO, Nastalek P et al. Prevalence and burden of chronic bronchitis symptoms: results from the BOLD studyEuropean Respiratory Journal 2017; 50 (5): 1700621.

[25] Enright P. A homeopathic remedy for early COPD. Respiratory Medicine 2011; 105 : 1573-1575.

Received: 21 Jul, 2019. Accepted: 19 Sep 2019
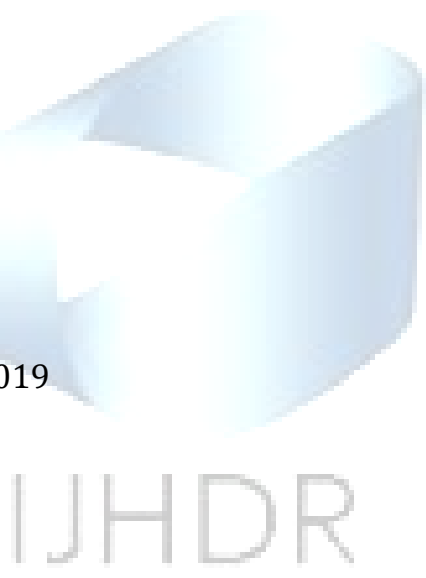

(C) International Journal of High Dilution Research.

Not for commercial purposes. 